\title{
Beneficial Effects of Piperine in global cerebral ischemia/reperfusion model in irradiated rats
}

\author{
Samar Saad Azab ${ }^{\mathrm{a}}$, Walaa Adel El-Sabbagh ${ }^{\mathrm{b}}$, Mohamed M. Abdel-Daim ${ }^{\mathrm{c}}$, Engy \\ Refaat Rashed $^{\mathbf{b}^{*}}$ \\ a: Department of Pharmacology and Toxicology, Faculty of Pharmacy, Ain Shams \\ University, Cairo, Egypt ${ }^{b}$ : Department of Drug Radiation Research, National Center \\ for Radiation Research and Technology, Egyptian Atomic Energy Authority, Cairo, \\ Egypt ${ }^{c}$ : Department of Pharmacology, Faculty of Veterinary Medicine, Suez Canal \\ University, Ismailia Governorate, Egypt
}

\begin{abstract}
Stroke is the third cause of death and a leading cause of chronic disability all around the

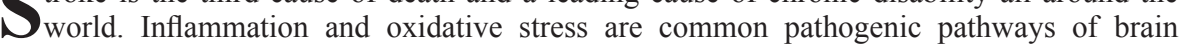
injury induced by ischemia/reperfusion (I/R). This work aims to investigate the possible role of Piperine as antioxidant and anti-inflammatory in attenuating the cerebral ischemia/ reperfusion (I/R)-induced brain injury in whole body $\gamma$-irradiated rats. Global cerebral ischemia was induced in both irradiated and non-irradiated male Wistar rats, and was followed by reperfusion. The beneficial effect of pretreatment with piperine $(10 \mathrm{mg} / \mathrm{kg}$, once daily p.o. for 15 days) was examined on cerebral ischemia-induced brain injury in $24 \mathrm{~h}$ pre-irradiated (6 Gy) male Wistar rats. I/R increased brain content of malondialdehyde (MDA) and decreased its glutathione (GSH) content and total antioxidant capacity (TAC). It also raised serum lactate dehydrogenase (LDH) activity and brain cytosolic calcium $\left(\mathrm{Ca}^{2+}\right)$ level. Pre-treatment with piperine significantly attenuated brain injury in $\mathrm{I} / \mathrm{R}$ irradiated rats by decreasing cytosolic brain calcium level and serum lactate dehydrogenase (LDH) activity. In addition, a significant decrease in nuclear factor kappa-B (NF-kB) was recorded in piperine treated group. These findings indicate that administration of piperine ameliorated most of the tested biochemical changes induced by $\mathrm{I} / \mathrm{R}$ in irradiated rat brain and serum.
\end{abstract}

Keywords: cerebral ischemia/reperfusion, gamma radiation, piperine, inflammation, oxidative stress

\section{Introduction}

Stroke has been reported to affect over 15 million people around the world leading to cerebral damage and chronic disability (Liang et al., 2011). Reperfusion of ischemic tissue may cause systemic injury, leading to multiple organ dysfunctions or even death, re-entrance of blood into tissues causes the release of oxygen free radicals (FRs) and inflammatory mediators, contributing to both local and systemic injuries. These injuries might become obvious, particularly in myocardial, renal, pulmonary and brain tissues (Blaisdell 2002; Harman et al., 2012).

Ischemia/reperfusion (I/R)-induced cerebral injury has been reported as a leading cause of death and long-term disabilities with consequent impact on the quality of life. Among the factors involved in the pathogenesis of $\mathrm{I} / \mathrm{R}$ injury are glutamate receptor-mediated excitotoxicity, energy failure, lactic acidosis, enhanced formation of free radicals, and cellular calcium homeostasis disturbance (Harukuni and Bhardwaj, 2006; Hicks and Jolkkonen, 2009; Abd El-Fattah et al., 2010). Cerebral ischemia in animal models leads to destruction of the blood-brain barrier (BBB) and edema (Keshavarz and Dehghani, 2017). This, consequently, results in the secretion of pro-inflammatory cytokines, TNF- $\alpha$, IL- $1 \beta$, and IL-6 in the ischemic region by activated immune cells, which drive and accelerate additional inflammatory processes via the activation of pro-inflammatory genes expression; such as, cyclooxygenase-2 (COX-2), nitric oxide synthase (NOS-2) and nuclear factor-kappa B (NF-kB) $(\mathrm{Tu}$ et al., 2010; Mohammadi et al., 2011).

induction have been described by various studies (Kojima et al., 1997; Leibowitz et al., 2011; Najafi et al., 2016). Radiation-induced

\footnotetext{
*: Corresponding Author; e-mail: engyrefaat@yahoo.com

DOI :10.21608/ejrsa.2017.2052.1026

(C)2017 National Information and Documentation Center (NIDOC)
} 
central nervous tissue (CNS) injury is thought to induce specific cytokines recovery/repair in response to radiation-induced oxidative stress (Tofilon and Fike, 2000).

Piper longum L. has been used as a crude drug in folk medicine to improve intestinal disorders, asthma, and poor peripheral blood circulation in Asia. In addition, piperine (1-peperoylpiperidine), the primary lipophilic principle in black pepper (Piper nigrum) and long pepper (Piper longum), has been reported to be effective against metabolic syndrome (Diwan et al., 2001) and displayed an anti-inflammatory activity (Pradeep and Kuttan, 2004). Piperine also possesses potent antidepressant-like properties (Li et al., 2007) and can activate whole-cell currents in rat sensory neurons; this suggests that piperine might be a good pharmacological candidate for acute neurodegenerative diseases (Szallasi 2005).

However, the role of piperine against I/Rinduced cellular damage is still not well defined. Therefore, this study was designed to investigate the possible role of piperine in ameliorating the biochemical changes in the brain and serum induced by cerebral $\mathrm{I} / \mathrm{R}$ in whole body $\gamma$-irradiated rats. The study is carried out in order to highlight the probable beneficial effects of the usage of a dietary antioxidant as adjuvant therapy in cancer patients receiving radiotherapy, especially those who have risk factor(s) for stroke; and in order to ameliorate one or more of the side-effects of radiotherapy and/ or lower the morbidity induced by stroke.

\section{Experimental Animals:}

Male albino rats of Wistar strain, weighing 150-200 g were used in this study. They were purchased from the Egyptian organization for biological products and vaccines (Cairo, Egypt) and the animals were maintained at the animal house of the National Center for Radiation Research and Technology, Atomic Energy Authority. Animals were maintained at $25-28{ }^{\circ} \mathrm{C}$ with a natural light/ dark cycle. Rats were provided with a standard rat pellets (El Nasr co. Egypt) and water ad libitum. All the experimental procedures conducted herein followed the ethics prepared by INSA, Animal Welfare Division of the Ministry of Environment \& Forest, Council of International Organization of Medical Sciences (WHO/UNESCO), NIH and PHS. The experimental protocol of the present study has been approved by the ethics committee

Egypt. J. Rad. Sci. Applic., Vol. 30, No.1(2017) at Faculty of Pharmacy, Ain Shams University [Committee approval no 8].

\section{Irradiation process}

Rats were exposed to 6 Gy single dose whole body gamma irradiation. Irradiation was performed using Cesium-137 irradiation unit (Gamma cell-40) produced by the Atomic Energy of Canada Limited, at a dose rate of $0.5 \mathrm{~Gy} / \mathrm{min}$.

Induction of global cerebral ischemia/reperfusion

Rats were subjected to bilateral carotid artery occlusions for $60 \mathrm{~min}$. using blunt mini clamps under urethane anesthesia ( $1 \mathrm{~g} / \mathrm{kg} ;$ i.p.) (Guedes and de Vasconcelos, 2008) followed by declamping of both arteries to allow reperfusion for another $60 \mathrm{~min}$. Animals temperature was estimated by rectal thermometer and maintained between $37^{\circ} \mathrm{C}$ and $38^{\circ} \mathrm{C}$ using heating lamp. Sham operated rats were treated identically without occluding carotid arteries (Vanella et al., 1990).

\section{Experimental design}

Animals were randomly divided into six experimental groups, eight rats each. Group I; normal sham operated group, the anaesthetized rats were subjected to all the surgical manipulations performed in the ischemic/reperfused groups, except that the occlusion of the common carotid arteries was not carried out. Group II; ischemic/ reperfused group; cerebral $\mathrm{I} / \mathrm{R}$ was induced in this group of rats as detailed above. Group III; irradiated sham operated group; rats were exposed to whole body $\gamma$-radiation at a dose level of $6 \mathrm{~Gy}$ and sham operated 24 hours later. Group $\mathrm{IV}$; irradiated ischemic/reperfused group, I/R was induced in rats $24 \mathrm{hr}$ following whole body $\gamma$-irradiation ${ }^{6}$; Group V; piperine treated irradiated ischemic/reperfused group, rats were treated with piperine $(10 \mathrm{mg} / \mathrm{kg}$, orally for 15 days, single dose daily) suspended in corn oil ( $2 \mathrm{ml} / \mathrm{Kg}$ ) (Vaibhav et al., 2012), on day 16 , rats were irradiated and $\mathrm{I} / \mathrm{R}$ was induced on day 17. Group VI; vehicle treated control group, rats were treated with corn oil (2 $\mathrm{ml} / \mathrm{Kg}$, orally for 15 days, single dose daily), then irradiated and rendered ischemic as detailed for Group V.

\section{Samples collection}

At the end of the reperfusion period, the animals were sacrificed by decapitation and their skulls were split on ice. The bodies of sacrificed rats were refrigerated till incineration. Serum samples were stored in aliquots at $-20^{\circ} \mathrm{C}$ till use. The separated sera were used for the determination 
of lactate dehydrogenase (LDH) activity (Howell et al., 1979) and total antioxidant capacity (TAC) via colorimetric reagent kit (Biodiagnostic, Egypt) (Koracevic et al., 2001).

The whole brain of each animal was separated, the left hemisphere was weighed and homogenized in ice cold normal saline $(20 \% \mathrm{w} / \mathrm{v}$ homogenate $)$ and was used for determination of brain contents of malondialdehyde (Yoshioka et al., 1979), reduced glutathione (Beutler et al., 1963) and total protein by colorimetric reagent kits and the supernatant was used for determination of NF- $\kappa B$ using ELISA kit specific for rats (MyBiosource Inc., USA), myeloperoxidase enzyme (MPO) activity using colorimetric activity assay kit (Leinco technologies Co.).

One $\mathrm{ml}$ of brain homogenate was mixed with an equal volume of cold tris-etheylene diamine tetracetic acid (EDTA) buffer $\mathrm{pH}$ 7.6, centrifuged at $105,000 \mathrm{xg}$ for $15 \mathrm{~min}$ at $4^{\circ} \mathrm{C}$ using SORVALL1 ULTRA 80 ultracentrifuge (DuPont Co., Delaware, USA). The separated cytosolic fraction was used for the determination of cytosolic calcium concentration using the atomic absorption technique (Subramania 1995).

Autopsy samples $(5 \mu \mathrm{m})$ were taken from the brain of rat in different groups and fixed in $10 \%$ formol saline (v/v) for twenty four hours. Washing was carried out using tap water then serial dilutions of alcohols (methyl, 70\% ethyl, and absolute ethyl alcohol) were used for dehydration. Specimens were cleared in xylene and embedded in paraffin at $56{ }^{\circ} \mathrm{C}$ in hot air oven for twenty four hours. Paraffin/beeswax tissue blocks were prepared for sectioning at 4 microns thickness by sledge microtome. The obtained tissue sections were collected on glass slides, deparaffinized, and stained by hematoxylin \& eosin stain for routine examination using a light electric microscope (Bancroft et al., 1996).

\section{Data analysis}

Results are expressed as means \pm standard error (S.E.). Data were analyzed using one way ANOVA followed by Tukey-Kramer multiple comparison test. The $\mathrm{p}$ value was considered significant at $\mathrm{p}<0.05$. Graphpad prism 6 software was used to carry out these statistical tests.

\section{Results}

Results of the current work showed that each of whole body $\gamma$-irradiation, cerebral I/R induced a significant increase in serum LDH activity and brain cytosolic $\mathrm{Ca}^{2+}$ which amounted to 2- and 18 -fold in I/R group and to about 2 - and 17 - fold in Rad group, as compared to the sham operated group, respectively. Moreover, combination of irradiation and cerebral $\mathrm{I} / \mathrm{R}$ showed a further significant increase in both serum LDH activity and brain cytosolic $\mathrm{Ca}^{2+}$ as compared to the sham operated group amounting to $236 \%$ and $2065 \%$, respectively (Figure 1).
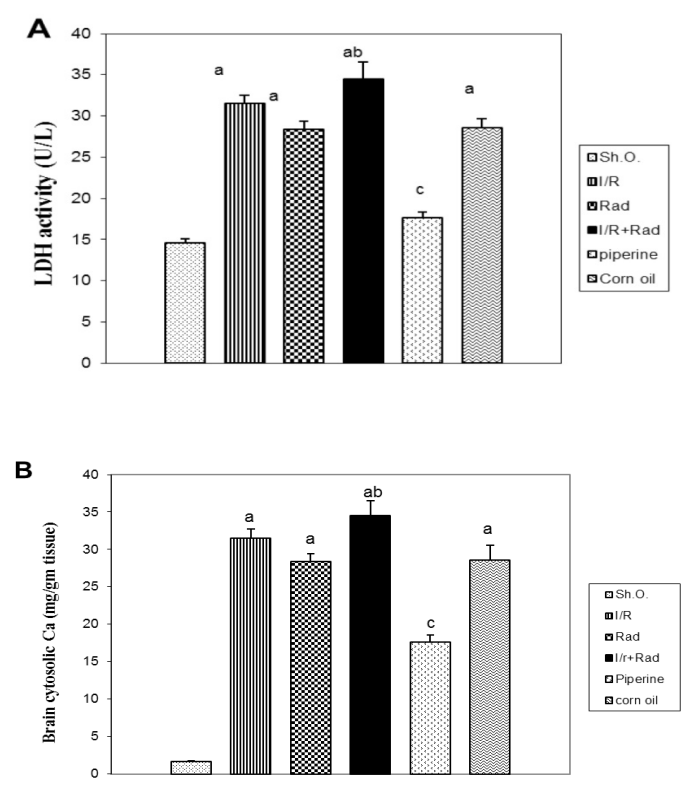

Fig. 1. Effect of Piperine on serum lactate dehydrogenase activity (LDH) (A) and brain cytosolic calcium (B) in irradiated cerebral ischemic/reperfused male rats. Values are expressed as mean \pm S.E.. $p<0.05$; a: significant difference from Sh.O. group, b: significant difference from $\mathrm{I} / \mathrm{R}$ group, c: significant difference from $\mathrm{Rad}+\mathrm{I} / \mathrm{R}$ group. [Sh.O.: Sham operated group; I/R: ischemic/ reperfused group; Rad: Irradiated group; $\mathrm{Rad}+$ I/R: irradiated ischemic/reperfused group].

On the other hand, an inflammatory response was observed in brain tissues of ischemic, irradiated and ischemic irradiated rats as compared to sham operated ones, which was indicated by a significant increase in MPO activity. NF- $\mathrm{BB}$ was observed in each of these groups. MPO activity amounted to $350 \%, 300 \%$ and $420 \%$ of the sham operated value, respectively. As for NF- $\kappa \mathrm{B}$ expression, it reached $340 \%, 250 \%$ and $360 \%$ as compared to the sham operated group, respectively (Figure 2).

Egypt. J. Rad. Sci. Applic., Vol. 30, No.1(2017) 


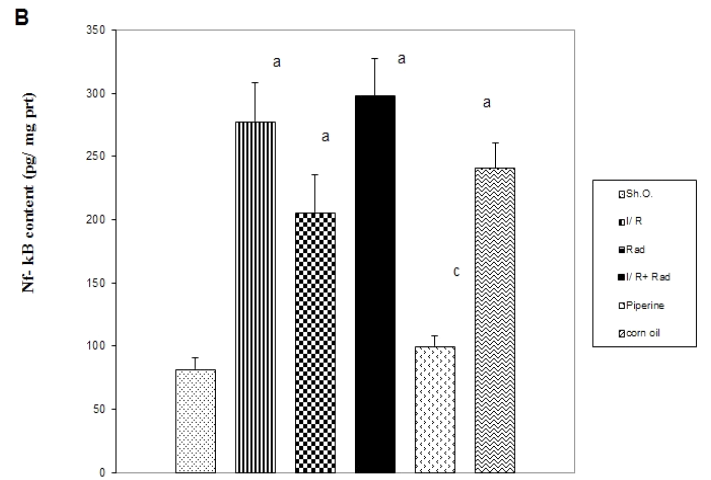

A

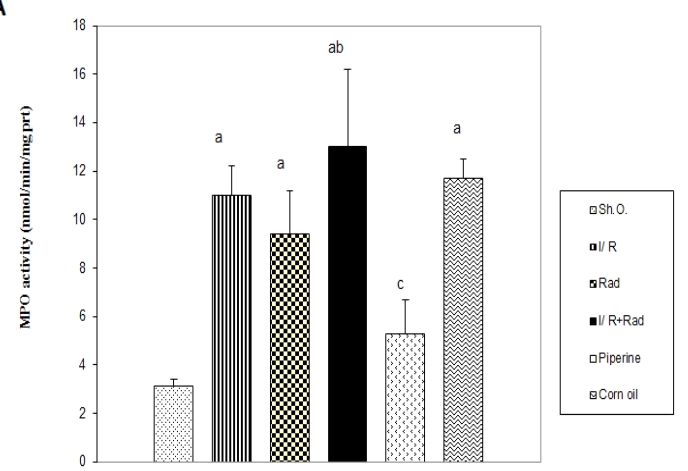

Fig. 2. Effect of Piperine on brain myeloperoxidase activity (MPO) (nmol/min/mg prt) (A) and brain nuclear factor-kappa B (Nf-kB) (pg/ mg prt) (B) in irradiated cerebral ischemic/ reperfused male rats. Values are expressed as mean \pm S.E.M and significance was ascertained as $P<0.05$; a: significant difference from Sh.O. group, b: significant difference from I/R group, c: significant difference from Rad + I/R group. [Sh.O.: Sham operated group; I/R: ischemic reperfused group; Rad: irradiated group; $\mathrm{Rad}+\mathrm{I} / \mathrm{R}$ : irradiated ischemic reperfused group].

In line with this, a marked state of oxidative stress has been observed in rat brain as a result of $\mathrm{I} / \mathrm{R}$, irradiation and their combination. This state was indicated by the rise in brain MDA content with a concomitant depletion of GSH and TAC. Brain MDA amounted to $260 \%, 450 \%$ and $600 \%$ of the sham operated value in I/R, Rad and $\mathrm{Rad}$ $+\mathrm{I} / \mathrm{R}$ groups, respectively. On the other hand, brain GSH content decreased to $51 \%, 57 \%$ and $44 \%$ of the sham operated value in $\mathrm{I} / \mathrm{R}, \mathrm{Rad}$ and $\mathrm{Rad}+\mathrm{I} / \mathrm{R}$ groups, respectively. Meanwhile, brain TAC decreased to $70 \%, 57 \%$ and $29 \%$ of the sham operated value in I/R, Rad and $\mathrm{Rad}+\mathrm{I} / \mathrm{R}$ groups, respectively (Table I).
However, pretreatment of rats with piperine for 15 successive days prior to irradiation and induction of $\mathrm{I} / \mathrm{R}$ resulted in a significant amelioration of brain damage. As for the inflammatory response, piperine induced a significant inhibition of MPO activity and NF$\kappa \mathrm{B}$ expression, their values amounted to $40 \%$ and $33 \%$ of the $\mathrm{Rad}+\mathrm{I} / \mathrm{R}$ group (Figure 2 ). In line with this, serum LDH activity and brain cytosolic $\mathrm{Ca}^{2+}$ showed a significant decrement in piperine treated group amounting to $51 \%$ and $55 \%$ of the ischemic irradiated group (Figure 1). Regarding the oxidative stress, piperine induced a decrement in MDA and an increment in each of GSH and TAC, these parameters amounted to about 55\%, $180 \%$ and $300 \%$ of the $\mathrm{Rad}+\mathrm{I} / \mathrm{R}$ group value, respectively (Table 1).

Histopathological examination of brain tissues revealed that the brain of sham operated rats showed a normal cerebral cortex with normal neuronal cells that appeared rounded with large vesicular nuclei (Fig. 3 a). Meanwhile, brain of Rad group revealed neuronal degeneration and neuronophagia associated with satellitosis (Fig. $3 \mathrm{~b}$ ) and proliferation of glial cells in addition to congestion of cerebral blood vessels. Brain of $\mathrm{I} / \mathrm{R}$ rats revealed a wide spread neuronal cell necrosis in which the affected neurons appeared shrunken with intensely eosinophilic cytoplasm and small dark basophilic nuclei associated with neuronophagia of the necrotic neurons (Fig. $3 \mathrm{c}$ ) and vacuolation of the neurophils. Neuronophagia and satellitosis as well as focal cerebral hemorrhages were frequently demonstrated in this group. Severe histopathological alterations were demonstrated in $\mathrm{Rad}+\mathrm{I} / \mathrm{R}$ group characterized by eosinophilic neuronal cell necrosis associated with neuronophagia (Fig. 3 d), satellitosis and proliferation of glial cells. A significant improvement of histopathological alterations was observed in $\mathrm{Rad}+\mathrm{I} / \mathrm{R}+$ piperine group characterized by sparse necrotized neuronal cells (Fig. 3 e) with no evidence of cerebral hemorrhage. Brain of vehicle pretreated group revealed an individual neuronal degeneration (Fig. $3 \mathrm{f}$ ) associated with proliferation of glial cells. 
TABLE 1. Effect of piperine on plasma total antioxidant capacity (TAC) and brain contents of malondialdehyde (MDA) and reduced glutathione (GSH) in cerebral ischemic/reperfused irradiated male rats

\begin{tabular}{|l|c|c|c|}
\hline $\begin{array}{l}\text { Parameter } \\
\text { Groups }\end{array}$ & $\begin{array}{c}\text { Brain GSH } \\
(\mathbf{m g} / \mathbf{g} \text { wet tissue) }\end{array}$ & $\begin{array}{c}\text { Brain MDA } \\
(\mathbf{n m o l} / \mathbf{m g} \mathbf{~ p r t})\end{array}$ & $\begin{array}{c}\text { Plasma TAC } \\
\text { (mmol/L) }\end{array}$ \\
\hline Sh. O. & $1.41 \pm 0.16^{-1}$ & $2.41 \pm 0.36$ & $47.26 \pm 5.37$ \\
\hline $\mathrm{I} / \mathrm{R}$ & $0.72 \pm 0.09^{\mathrm{a}}$ & $6.261 .48 \pm^{\mathrm{a}}$ & $32.71 \pm 2.98^{\mathrm{a}}$ \\
\hline $\mathrm{Rad}$ & $0.81 \pm 0.06^{\mathrm{a}}$ & $10.85 \pm 1.63^{\mathrm{a}}$ & $27.29 \pm 1.94^{\mathrm{a}}$ \\
\hline $\mathrm{Rad}+\mathrm{I} / \mathrm{R}$ & $0.62 \pm 0.07^{\mathrm{a}}$ & $14.69 \pm 2.55^{\mathrm{ab}}$ & $13.73 \pm 1.64^{\mathrm{ab}}$ \\
\hline $\mathrm{Rad}+\mathrm{I} / \mathrm{R}+$ Piperine & $1.12 \pm 0.21^{\mathrm{c}}$ & $8.101 .01 \pm^{\mathrm{c}}$ & $40.92 \pm 3.78^{\mathrm{c}}$ \\
\hline $\mathrm{Rad}+\mathrm{I} / \mathrm{R}+$ Corn Oil & $0.97 \pm 0.14^{\mathrm{a}}$ & $11.29 \pm 2.12^{\mathrm{a}}$ & $15.92 \pm 3.12^{\mathrm{a}}$ \\
\hline
\end{tabular}

Values are expressed as mean \pm standard error of mean (SEM), $p<0.05$; a: significant difference from Sh.O. group, b: significant difference from I/R group, c: significant difference from Rad + I/R group. [Sh.O.: Sham operated group; I/R: ischemic/reperfused group; Rad: Irradiated group; $\mathrm{Rad}+\mathrm{I} / \mathrm{R}$ : irradiated ischemic/reperfused group].
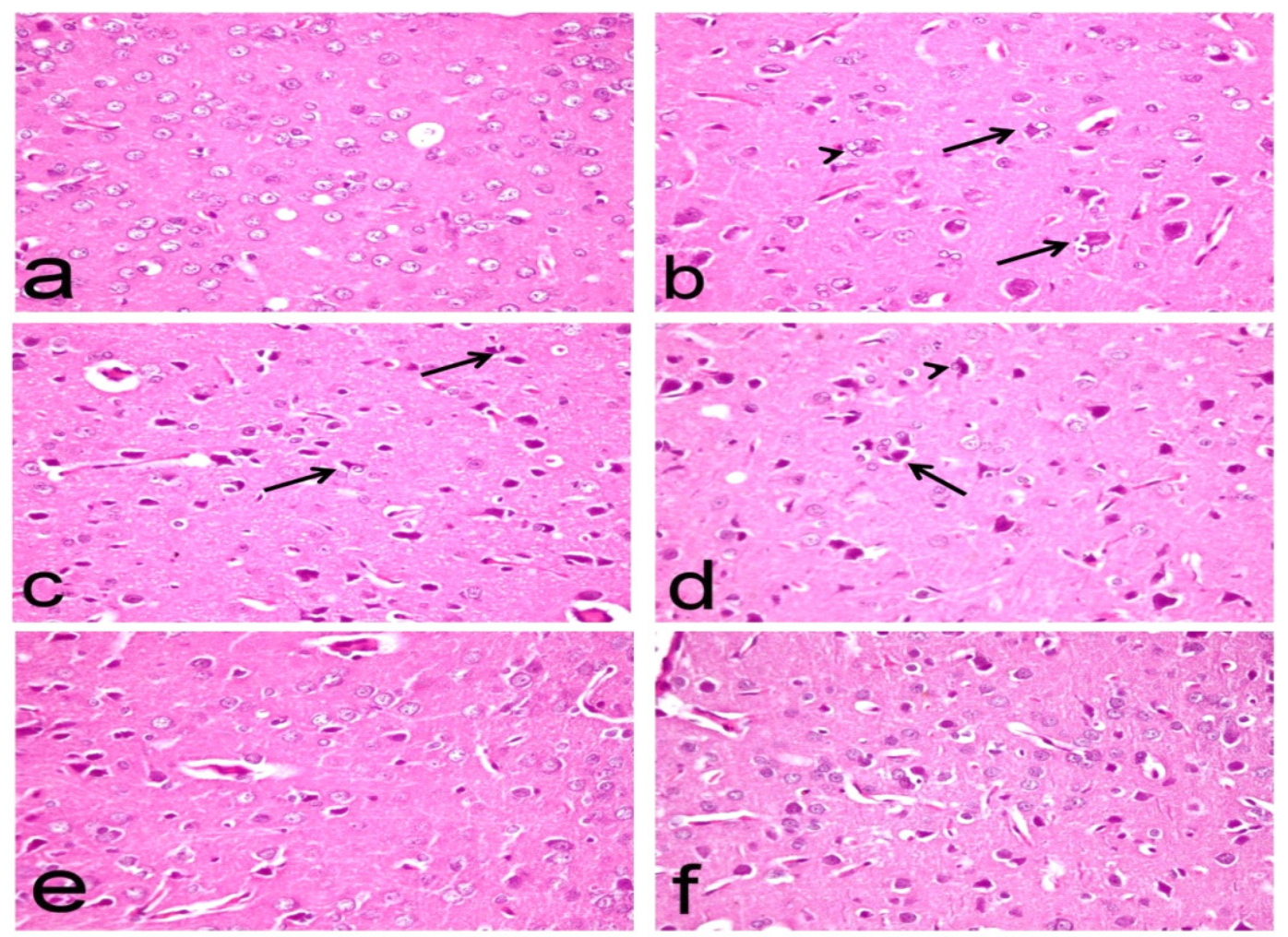

Fig. 3. Brain of (a) Sham operated group showing normal rounded neuronal cells, (b) Rad group showing a neuronal degeneration and neuronophagia (arrow) associated with satellitosis (arrow head), (c) I/R group showing a neuronal cell necrosis with neuronophagia of the necrotic neurons (arrow), (d) Rad + I/R treated rats showing an eosinophilic neuronal cell necrosis (arrow) associated with neuronophagia (arrow head), (e) $\mathbf{R a d}+\mathbf{I} / \mathbf{R}+$ Piperine group showing sparse necrosed neuronal cells, (f) $\mathbf{R a d}+\mathbf{I} / \mathbf{R}+$ Corn oil group showing an individual neuronal degeneration. (H\&E, X400) 


\section{Discussion}

Ischemic reperfusion model in this study showed an increase in serum LDH activity, brain cytosolic $\mathrm{Ca}^{2+}$, MPO level and NF- $\kappa \mathrm{B}$ this was in accordance with the results reported in previous studies (Matsuo et al., 1994; Stephenson et al., 2000; Xu et al., 2014). The ischemia-induced interruption of blood and oxygen supply leads to inhibition of aerobic glucose metabolism with a subsequent accumulation of lactate resulting in increased LDH activity to metabolize the formed lactate (Shaheen et al., 1996). Moreover, cells become dependent on anaerobic glycolysis for their ATP supply leading to an accumulation of lactate, protons, and $\mathrm{NAD}^{+}$and, therefore, cause a drop in cytosolic $\mathrm{pH}$. In an attempt to reestablish normal $\mathrm{pH}$, the cell extrudes $\mathrm{H}+$ ions in exchange for $\mathrm{Na}^{+}$via $\mathrm{Na}^{+} / \mathrm{H}^{+}$exchanger (Murphy and Steenbergen, 2008). The $\mathrm{Na}^{+}$ions are, in turn, exchanged for $\mathrm{Ca}^{2+}$ by the $\mathrm{Na}^{+} / \mathrm{Ca}^{2+}$ exchanger. The endoplasmic/sarcoplasmic reticulum (ER/SR) $\mathrm{Ca}^{2+}$ store is also affected during I/R. In particular, $\mathrm{Ca}^{2+}$ reuptake into the ER/SR by the SERCA ATPase is impaired by $\mathrm{I} / \mathrm{R}$, whereas $\mathrm{Ca}^{2+}$ release through the ryanodine receptor is enhanced, both of which further exacerbate the lethal elevations in cytosolic $\mathrm{Ca}^{2+}$. These massive alterations in $\mathrm{Ca}^{2+}$ activate a variety of systems, all of which can contribute to cell death following I/R (Szydlowska and Tymianski, 2010; Sanada et al., 2011).

Increased intracellular $\mathrm{Ca}^{2+}$ also leads to the generation of calcium pyrophosphate complexes and the formation of uric acid, both of which belong to a group of "danger signals" that bind to the intracellular protein complexes called inflammasomes. Inflammasomes mediate, an increased production of cytokines, such as IL-1 $\beta$ and TNF $\alpha$, which, in turn, activates transcription factors; e.g., Nuclear Factor-kappa B (NF-кB) to increase the expression of additional cytokines and chemokines, thereby precipitating a cytokine storm that exacerbates I/R injury (Kalogeris et al., 2012).

In the current work, $\mathrm{I} / \mathrm{R}$ resulted in a decrease in rat brain total antioxidant capacity and brain GSH level as well as an increase in brain MDA level, reflecting an increase in oxidative stress state. In line with this, I/R-induced hypoxia and diminished energy supply have been reported to result in blood brain barrier rupture, reactive oxygen species (ROS) generation, recruitment of inflammatory molecules, and cell death by necrosis and apoptosis (Kataoka et al., 2004;
Yasuda et al., 2011). Also, I/R has been reported to induce a marked enhancement of oxidative stress in a variety of organs (Muñoz-Casares et al., 2006, Abogresha et al., 2016). Mechanistically, reperfusion and reoxygenation of tissues in the presence of hypoxanthine and xanthine oxidase lead to production of aggressive oxygen radicals (Marian et al., 2007; Yildirim et al., 2009).

Irradiated rats showed an exacerbated cerebral damage after I/R as compared to the non-irradiated ones, this was in accordance with the findings of Abd El-Fattah et al. (2010) and Suresh et al. (2015). Irradiation has been proved to induce a neuro-inflammatory response, which spread from the site of injury to relatively remote regions of the central nervous system. Moreover, irradiation induces neural-precursor cells dysfunction by altering the microenvironment that regulates their fate and proliferative capacity. In addition, the remaining of non-irradiated neural precursor cells fail to differentiate into neurons in the irradiated hippocampus (Suresh et al., 2015).

In the present study, the inflammatory response observed in brain tissues following irradiation and ischemia is in accordance with earlier studies' findings which reported elevated levels of IL-1 $\beta$, IL-6, and TNF- $\alpha$ in ischemic brain and serum. Further, these pro-inflammatory cytokines contents were much higher in ischemic brain tissues than those in serum. This indicates that $I / R$ injury resulted in an elevated level of cytokines in brain and due to breakdown of blood-brain barrier (BBB), cytokines are also secreted into blood. In agreement with this, several studies have also reported that pro-inflammatory cytokines, including TNF- $\alpha$ and IL- $1 \beta$ are elevated in serum in the early phase of acute ischemic stroke (Yasuda et al., 2011; Oto et al., 2008). These molecules recruit more circulating leukocytes and promote accumulation of neutrophils, macrophages, and activated microglia, which infiltrate the ischemic region and lead to a further loss of neuronal cells and brain tissue, thereby possibly enlarging the cerebral infarct area (Chapman et al., 2009; Denes et al., 2010; Emsley et al., 2005; Gong et al., 2014).

In the current study, irradiation of animals affected the brain levels of GSH and MDA due to the oxidative stress which results from exposure to radiation. In addition, $\gamma$-irradiation induced more severe biochemical derangements in ischemic reperfused rats as evidenced by the 
pronounced increase in both brain LDH activity and cytosolic $\mathrm{Ca}^{2+}$ level and exacerbation of brain oxidative stress status. The rise in enzyme activity in this study could be a result of radiation-induced inhibition of cellular respiration (Nosov et al., 1999) with a subsequent increase in the rate of glycolysis and LDH activity.

Piperine administration to $\mathrm{I} / \mathrm{R}$ or $\mathrm{Rad}+\mathrm{I} / \mathrm{R}$ irradiated rats in this study showed a significant increase in total antioxidant capacity and reduced GSH level as well as a decrease in brain MDA level. Vaibhav et al. (2012) reported that piperine administration to rats followed by (I/R) injury showed a significantly less infarct area observed in rat brain after $\mathrm{I} / \mathrm{R}$ injury. Piperine has been demonstrated in both in vivo and in vitro experiments to protect against oxidative damage by quenching free radicals and ROS and inhibiting lipid peroxidation (Yang et al., 2015; Mittal and Gupta, 2000). Selvendiran et al. (2004) investigated the impact of piperine on alterations of the mitochondrial antioxidant system and lipid peroxidation. Oral supplementation of piperine revealed a decrease in the extent of mitochondrial lipid peroxidation and concomitant increase in the activities of enzymatic antioxidants and nonenzymatic antioxidants. They reported that piperine modulates lipid peroxidation and increases the antioxidant defense system. Moreover, Vijayakumar et al. (2004) examined the effect of supplementation of black pepper or piperine on tissue lipid peroxidation and enzymic and non-enzymic antioxidants in rats fed a high-fat diet, and they observed that these spices can reduce high-fat diet-induced oxidative stress. They also observed that simultaneous supplementation with black pepper or piperine lowered thiobarbituric acid reactive substances and conjugated dienes levels and maintained SOD, catalase, GSH, glutathione-S-transferase, and reduced glutathione levels near to those of control rats.

Regarding the anti-inflammatory effect of piperine, observed herein, it is in accordance with the results reported in earlier studies (Kim et al., 2012; El-Ghazaly et al., 2016; Gupta et al., 2015). As for its supposed mechanism of action, piperine has been shown to inhibit the expression of cyclooxygenase-2 (COX-2) a key enzyme in the arachidonic acid (AA) metabolic pathway, resulting in a decreased production of prostaglandins E-2 (PGE-2) in the inflammatory responses (Kim et al., 2012). In line with this, a recent study investigated a possible anti-platelet mechanism of piperine through the modulation of the AA metabolic pathway. They compared the effects of piperine on the liberation of AA and the activities of AA-metabolizing enzymes in collagen-stimulated platelets and LPS-stimulated cells. In addition, piperine has been reported to inhibit collagen- and AA-induced platelet aggregation through the inhibition of their platelet activation cascades (Son et al., 2014).

\section{Conclusion}

Findings of the present study indicated that piperine supplementation provided promising beneficial effects against most of the biochemical changes induced by $\mathrm{I} / \mathrm{R}$ in irradiated rat brain and serum. These effects are probably mediated through both its anti-inflammatory and antioxidant actions.

Acknowledgement: Authors of this work are deeply grateful to Dr. Azza Hassan; Assistant Professor of histopathology, Faculty of Veterinary Medicine, Cairo University, for her efforts in the assessment of the histopathological examinations of brain sections that was carried out in the present study.

Disclosure of interest: The authors declare that they have no competing interests among them.

\section{References}

Abd El-Fattah A.A., El-Sawalhi M.M., Rashed E.R. and El-Ghazaly M.A. (2010) Possible role of vitamin $\mathrm{E}$, coenzyme Q10 and rutin in protection against cerebral ischemia/reperfusion injury in irradiated rats. Int. J. Radiat. Biol., 86, 1070-1078.

Abogresha N.M., Greish S.M., Abdelaziz E.Z., Khalil W.F. (2016) Remote effect of kidney ischemiareperfusion injury on pancreas: role of oxidative stress and mitochondrial apoptosis. Arch Med Sci., 12, 252-62.

Bancroft J.D., Stevens A. and Turner D.R. (1996) "Theory and Practice of Histological Technique", Churchill Livingston, San Francisco.

Beutler E, Duron O and Kelly BM. (1963) Improved method for the determination of blood glutathione. J. Lab. Clin. Med., 61, 882-888.

Blaisdell F.W. (2002) The pathophysiology of skeletal muscle ischemia and the reperfusion syndrome: a review. Cardiovasc. Surg., 10, 620-630.

Chapman K.Z., Dale V.Q., Denes A., Bennett G., Rothwell N.J., Allan S.M. and McColl Egypt. J. Rad. Sci. Applic., Vol. 30, No.1(2017) 
B.W. (2009) A rapid and transient peripheral inflammatory response precedes brain inflammation after experimental stroke. J. Cereb. Blood Flow Metab., 29, 1764-1768.

Denes A., Thornton P., Rothwell N.J. and Allan S.M. (2010) Inflammation and brain injury: acute cerebral ischaemia, peripheral and central inflammation. Brain Behav. Immun., 24, 708-723.

Diwan V., Poudyal H. and Brown L. (2011) Piperine attenuates cardiovascular, liver and metabolic changes in high carbohydrate, high fat-fed rats. Cell Biochem. Biophys., 67, 297-304.

El-Ghazaly M.A., Fadel N.A., Rashed E.R. and Kenawy S.A. (2016) Anti-inflammatory and antinociceptive effects of piperine in gamma-irradiated rats. Egypt J. Rad. Sci. Applic., 29, 1-17.

Emsley H.C., Smith C.J., Georgiou R.F., Vail A., Tyrrell P.J., Barberan E.M., Rothwell N.J., Hopkins S.J. (2005) Correlation of systemic inflammatory response with infarct volume in acute ischemic stroke patients. Stroke, 36, 228-229.

Gong G., Xiang L., Yuan L., Hu L., Wu W., Cai L., Yin L., Dong H. (2014) Protective effect of glycyrrhizin, a direct HMGB1 inhibitor, on focal cerebral ischemia/reperfusion-induced inflammation, oxidative stress and apoptosis in rats. PloS one, 9 , e89450

Guedes R.C. and de Vasconcelos C.A. (2008) Sleepdeprivation enhances in adult rats the antagonistic effects of pilocarpine on cortical spreading depression: a dose-response study. Neurosci. Lett., 442, 118-122.

Gupta R.A., Motiwala M.N., Dumore N.G., Danao K.R., Ganjare A.B. (2015) Effect of piperine on inhibition of FFA induced TLR4 mediated inflammation and amelioration of acetic acid induced ulcerative colitis in mice. J. Ethnopharmacol., 164, 239-246.

Harman F., Hasturk A.E., Yaman M., Arca T., Kilinc K., Sargon M.F. and Kaptanoglu E. (2012) Neuroprotective effects of propofol, thiopental, etomidate, and midazolam in fetal rat brain in ischemia-reperfusion model. Childs. Ner. Syst., 28, 1055-1062.

Harukuni I. and Bhardwaj A. (2006) Mechanisms of brain injury after global cerebral ischemia. Neurologic. Clinics., 24, 1-21.

Hicks A. and Jolkkonen J. (2009) Challenges and possibilities of intravascular cell therapy in stroke. Acta Neurobiol Exp., 69, 1-11.
Howell B.F., McCane S. and Schaffer R. (1979) Lactate to pyruvate or pyruvate to lactate assay for lactate dehydrogenase: a reexamination. Clin. Chem., 25, 269-272.

Kalogeris, T., Baines, C.P., Krenz, M. and Korthuis, R.J. (2012) Cell biology of ischemia/reperfusion injury. Int. Rev. Cell. Mol. Biol., 298, 229-317.

Kataoka H., Kim S.W. and Plesnila N. (2004) Leukocyte-endothelium interactions during permanent focal cerebral ischemia in mice. $J$. Cereb. Blood Flow Metab., 24, 668-676.

Keshavarz S. and Dehghani G.A. (2017) Cerebral Ischemia/Reperfusion Injury in the Hyperthyroid Rat. Iran J. Med. Sci., 42 (1), 48-56.

Kim H.G., Han E.H., Jang W.S., Choi J.H., Khanal T., Park B.H., Tran T.P., Chung Y.C. and Jeong H.G. (2012) Piperine inhibits PMA-induced cyclooxygenase-2 expression through downregulating NF- $\mathrm{BB}, \mathrm{C} / \mathrm{EBP}$ and AP-1 signaling pathways in murine macrophages. Food Chem. Toxicol., 50, 2342-2348.

Kojima S., Matsuki O., Kinoshita I., Gonzalez T.V., Shimura N. and Kubodera A. (1997) Does small-dose gamma-ray radiation induce endogenous antioxidant potential in vivo. Biol. Pharm. Bull., 20, 601-604.

Koracevic D., Koracevic G., Djordjevic V., Andrejevic S. and Cosic V. (2001) Method for the measurement of antioxidant activity in human fluids. J. Clin. Pathol., 54, 356-361.

Leibowitz B.J., Qiu W., Liu H., Cheng T., Zhang L., and Yu J. (2011) Uncoupling p53 functions in radiationinduced intestinal damage via PUMA and $\mathrm{p} 21 . \mathrm{Mol}$. Cancer Res., 9, 616-625.

Li S., Wang C., Wang M., Li W., Matsumoto K. and Tang Y. (2007) Antidepressant like effects of piperine in chronic mild stress treated mice and its possible mechanisms. Life Sci., 80, 1373-1381.

Liang X., Lin L., Woodling N.S., Wang Q., Anacker C., Pan T., Merchant M. and Andreasson K. (2011) Signaling via the prostaglandin E2 receptor EP4 exerts neuronal and vascular protection in a mouse model of cerebral ischemia. J. Clin. Invest., 121, $4362-4371$.

Marian V., Dieter L., Jan M., Cronin M.T., Mazur M. and Telser J. (2007) Free radicals and antioxidants in normal physiological functions and human disease. Intern. J. Biochem. Cell Biol., 39, 44-84. 
Matsuo Y., Onodera H., Shiga Y., Nakamura M., Ninomiya M., Kihara T., Kogure K. (1994) Correlation between myeloperoxidase-quantified neutrophil accumulation and ischemic brain injury in the rat, effects of neutrophil depletion. Stroke., 25, 1469-1475.

Mittal R. and Gupta R.L. (2000) In vitro antioxidant activity of piperine. Methods Find. Exp. Clin. Pharmacol., 22, 271-274.

Mohammadi M.T., Shid-Moosavi S.M. and Dehghani G.A. (2011) Contribution of nitric oxide synthase (NOS) in blood-brain barrier disruption during acute focal cerebral ischemia in normal rat. Pathophysiol., 19, 13-20.

Muñoz-Casares F., Padillo F., Briceño J., Collado J.A., Muñoz-Castañeda J.R., Ortega R., Cruz A., Túnez I., Montilla P., Pera C.and Muntané J. (2006) Melatonin reduces apoptosis and necrosis induced by ischemia/reperfusion injury of the pancreas. J. Pineal. Res., 40, 195-203.

Murphy E. and Steenbergen C. (2008) Mechanisms underlying acute protection from cardiac ischemiareperfusion injury. Physiol. Rev., 88, 581-609.

Najafi M., Fardid R., Takhshid M.A., Mosleh-Shirazi M.A., Rezaeyan A.H. and Salajegheh A. (2016) Radiation-induced oxidative stress at out-of-field lung tissues after pelvis irradiation in rats. Cell J., 18, 340-345.

Nosov A.V., Ivnitsky Y.Y. and Malakhovsky V.N. (1999) Metabolic correction of cerebral radiation syndrome. Radiat. Res., 152, 523-529.

Oto J., Suzue A., Inui D., Fukuta Y., Hosotsubo K., Torii M., Nagahiro S. and Nishimura M. (2008) Plasma proinflammatory and anti-inflammatory cytokine and catecholamine concentrations as predictors of neurological outcome in acute stroke patients. $J$. Anesth., 22, 207-212.

Pradeep C.R. and Kuttan G. (2004) Piperine is a potent inhibitor of nuclear factor-kappaB (NF-kappaB), c-Fos, CREB, ATF-2 and proinflammatory cytokine gene expression in B16F-10 melanoma cells. Int. Immunopharmacol., 4, 1795-1803.

Sanada S., Komuro I. and Kitakaze M. (2011) Pathophysiology of myocardial reperfusion injury: preconditioning, postconditioning, and translational aspects of protective measures. Am. J. Physiol. Heart Circ. Physiol., 301, H1723- H1741.

Selvendiran K., Senthilnathan P., Magesh V. and Sakthisekaran D. (2004) Modulatory effect of Piperine on mitochondrial antioxidant system in $\operatorname{Benzo}(\alpha)$ pyrene-induced experimental lung carcinogenesis. Phytomedicine., 11, 85-89

Shaheen A.A., Abd-El-Fattah A.A. and Seif-El-Nasr M. (1996) Influence of verapamil on the efficacy of vitamin $\mathrm{E}$ in preventing the ischemia/reperfusion biochemical dearrangement in cerebral cortex of rat. Arzneimittel. Forschung., 46, 670-677.

Son D.J., Akiba S., Hong J.T., Hong J.T., Yun Y.P., Hwang S.Y., Park Y.H. and Lee S.E. (2014) Piperine inhibits the activities of platelet cytosolic phospholipase A2 and thromboxane A2 synthase without affecting cyclooxygenase-1 activity: different mechanisms of action are involved in the inhibition of platelet aggregation and macrophage inflammatory response. Nutrients., 6, 3336-3352.

Stephenson D., Yin T., Smalstig E.B., Hsu M.A., Panetta J., Little S., Clemens J. (2000) Transcription factor nuclear factor-kappa B is activated in neurons after focal cerebral ischemia. J. Cereb. Blood Flow Metab., 20, 592-603.

Subramania R.S. (1995) Storage and preservation of blood and urine for trace element analysis: A review. Biol. Trace Elem. Res., 49, 187-210.

Suresh K.M.A., Peluso M., Chaudhary P., Dhawan J., Beheshti A., Manickam K., Thapar U., Pena L., Natarajan M., Hlatky L., Demple B. and Naidu M. (2015) Fractionated radiation exposure of rat spinal cords leads to latent neuro-inflammation in brain, cognitive deficits, and alterations in apurinic endonuclease. PloS one, 10, e0133016.

Szallasi A. (2005) Piperine: researchers discover new flavor in an ancient spice. Trends. Pharmacol. Sci., 26, 437-439.

Szydlowska K. and Tymianski M. (2010) Calcium, ischemia and excitotoxicity. Cell Calcium., 47, 122-129.

Tofilon P.J. and Fike J.R. (2000) The radioresponse of the central nervous system: A dynamic process. Radiat. Res., 153, 357-370.

Tu X.K., Yang W.Z., Shi S.S., Wang C.H., Zhang G.L., Ni T.R., Chen C.M., Wang R., Jia J.W. and Song Q.M. (2010) Spatio-temporal distribution of inflammatory reaction and expression of TLR $2 / 4$ signaling pathway in rat brain following permanent focal cerebral ischemia. Neurochem. Res., 35, $1147-1155$.

Vaibhav K., Shrivastava P., Javed H., Khan A., Ahmed M.E., Tabassum R., Khan M.M., Khuwaja G., Islam F., Siddiqui M.S., Safhi M.M. and Islam F. (2012) Piperine suppresses cerebral ischemia-

Egypt. J. Rad. Sci. Applic., Vol. 30, No.1(2017) 
reperfusion-induced inflammation through the repression of COX-2, NOS-2, and NF- $\kappa \mathrm{B}$ in middle cerebral artery occlusion rat model. Mol. Cell. Biochem., 367, 73-84.

Vanella, A., DiGicamo C. and Sorrenti V. (1990) Lipid peroxidation and xanthine dehydrogenase/ oxidase ratio in rat cerebral cortex during postischemic reperfusion: Effect of $\mathrm{Ca}^{2+}$ antagonist drugs. In: "Pharmacology of cerebral ischemia Stuttgart“ . Krieglstein J., Oberpichler H. (Eds.), Wissenschaftlische Verlagsgesellschaft, p.p. 311315 .

Vijayakumar R.S., Surya D. and Nalini N. (2004) Antioxidant efficacy of black pepper (Piper nigrum L.) and piperine in rats with high fat diet induced oxidative stress. Redox Rep., 9, 105-110.

Xu Y., Yang Y. and Luo Y.Q. (2014) Effect of atorvastatin on serum oxidative stress and $\mathrm{N}$-terminal brain natriuretic peptide expression in rats. Asian Pac. J. Trop. Med., 7, 398-401.
Yang W., Chen Y.H., Liu H., Qu H.D. (2015) Neuroprotective effects of piperine on the 1-methyl-4-phenyl-1,2,3,6-tetrahydropyridineinduced Parkinson's disease mouse model. Int. J. Mol. Med., 36, 1369-1376.

Yasuda Y., Shimoda T., Uno K., Tateishi N., Furuya S., Tsuchihashi Y., Kawai Y., Naruse S. and Fujita S. (2011) Temporal and sequential changes of glial cells and cytokine expression during neuronal degeneration after transient global ischemia in rats. J. Neuroinflamm., 8, 70-79.

Yildirim A., Tuncer M.C., Pamukçu O., Aktas A., Akkus M. (2009) Effects of ischemia/reperfusion on beta cells of pancreas and protective effects of melatonin treatment. Int. J. Morphol., 27, 519-525.

Yoshioka T., Kawada K., Shimada T., Mori M. (1979) Lipid peroxidation in maternal and cord blood and protective mechanism against activated-oxygen toxicity in the blood. Am. J. Obstet. Gynecol., 135, 372-376.

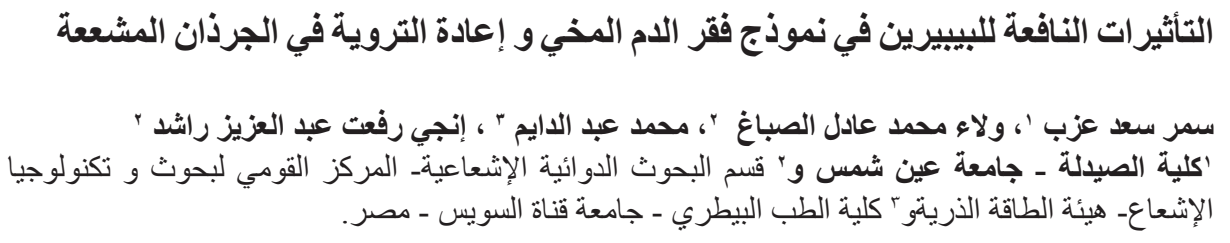

تمثل السكتة الدماغية السبب الثالث عالمياً للوفاة و هى سبب رئيسي من اسباب الاعاقة المزمنة. و يعد الإلتهاب

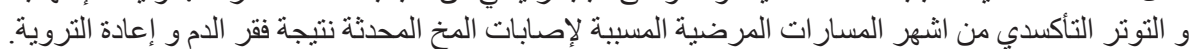

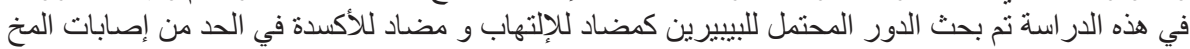

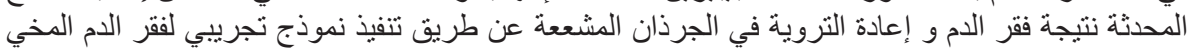

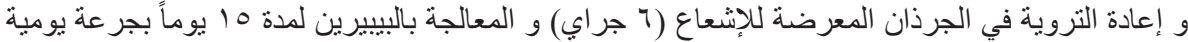

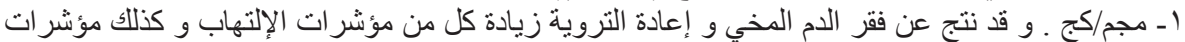

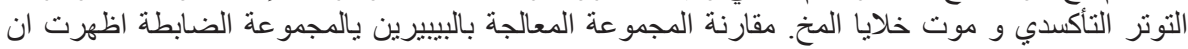

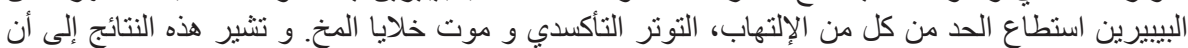

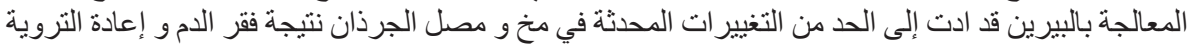

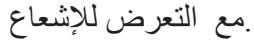

